\title{
Strong thermal stratification reduces detection efficiency and range of acoustic telemetry in a large freshwater lake
}

\author{
Yulong Kuai ${ }^{1}$, Natalie V. Klinard ${ }^{2,3}$, Aaron T. Fisk2 ${ }^{2}$ Timothy B. Johnson ${ }^{4}$, Edmund A. Halfyard ${ }^{5}$, Dale M. Webber ${ }^{6}$,
} Stephanie J. Smedbol ${ }^{6}$ and Mathew G. Wells ${ }^{1 *}$

\begin{abstract}
Background: The successful use of acoustic telemetry to detect fish hinges on understanding the factors that control the acoustic range. The speed-of-sound in water is primarily a function of density, and in freshwater lakes density is primarily driven by temperature. The strong seasonal thermal stratification in the Great Lakes represent some of the steepest sound speed gradients in any aquatic system. Such speed-of-sound gradients can refract sound waves leading to greater divergence of acoustic signal, and hence more rapid attenuation. The changes in sound attenuation change the detection range of a telemetry array and hence influence the ability to monitor fish. We use 3 months of data from a sentinel array of $\mathrm{V} 9$ and $\mathrm{V} 16$ Vemco acoustic fish tags, and a record of temperature profiles to determine how changes in stratification influence acoustic range in eastern Lake Ontario.
\end{abstract}

Result: We interpret data from an acoustic telemetry array in Lake Ontario to show that changes in acoustic detection efficiency and range correlate strongly with changes in sound speed gradients due to thermal stratification. The steepest sound speed gradients of $10.38 \mathrm{~m} \mathrm{~s}^{-1} / \mathrm{m}$ crossing the thermocline occurred in late summer, which caused the sound speed difference between the top and bottom of the water column to be greater than $60 \mathrm{~m} / \mathrm{s}$. V9 tags transmitting across the thermocline could have their acoustic range reduced from $>650 \mathrm{~m}$ to $350 \mathrm{~m}$, while the more powerful V16 tags had their range reduced from $>650 \mathrm{~m}$ to $450 \mathrm{~m}$. In contrast we found that when the acoustic source and receiver were both transmitting below thermocline there was no change in range, even as the strength of sound speed gradient varied.

Conclusion: Changes in thermal stratification occur routinely in the Great Lakes, on timescales between months and days. The acoustic range can be reduced by as much as 50\% compared to unstratified conditions when fish move across the thermocline. We recommend that researchers consider the influences of thermal stratification to acoustic telemetry when configuring receiver position.

Keywords: Acoustic telemetry, Detection efficiency, Detection range, Thermal stratification, Sound speed difference, Sound speed gradients, Sound attenuation

*Correspondence: m.wells@utoronto.ca

${ }^{1}$ Department of Physical and Environmental Sciences, University of Toronto Scarborough, Toronto, ON, Canada

Full list of author information is available at the end of the article

\section{Background}

Acoustic telemetry is a widely used tool to monitor fish movement and behaviour $[3,8]$ and understanding the performance of telemetry equipment is crucial for proper experimental design and interpretation of the data (e.g., [10]). One variable which impacts acoustic detection performance, particularly in freshwater lakes, is thermal original author(s) and the source, provide a link to the Creative Commons licence, and indicate if changes were made. The images or other third party material in this article are included in the article's Creative Commons licence, unless indicated otherwise in a credit line to the material. If material is not included in the article's Creative Commons licence and your intended use is not permitted by statutory regulation or exceeds the permitted use, you will need to obtain permission directly from the copyright holder. To view a copy of this licence, visit http://creativecommons.org/licenses/by/4.0/. The Creative Commons Public Domain Dedication waiver (http://creativeco mmons.org/publicdomain/zero/1.0/) applies to the data made available in this article, unless otherwise stated in a credit line to the data. 
stratification. It is well known that many lakes have seasonal thermal stratification, with warm surface waters and cooler waters at depth. This thermal stratification strongly influences fish movement and behaviour (e.g., [14, 21]). Furthermore, the associated sound speed gradients induced by temperature gradients also have implications to the detection efficiency of acoustic telemetry devices and detection range [16]. Here detection efficiency is defined as the ratio of acoustic signals detected out of the total signals transmitted, and detection range is the distance at which the detection efficiency drops to $50 \%$. Detection efficiency can be influenced by thermal stratification, because sound waves from an acoustic tag can refract and bend as they move from the epilimnion (warmer waters) to a receiver in the hypolimnion (cooler waters). Depending on how pronounced the sound speed gradients are, and the relative vertical locations of tagged fish and receivers, detection range may be significantly impacted in thermally stratified systems [25]. There are many factors potentially affecting detection efficiency, that may subsequently reduce detection range of acoustic telemetry. In previous studies, the effect of environmental noise, biological noise, and artificial noise has been shown to reduce detection efficiency $[10,11,15]$. Thermal stratification can also influence the performance of acoustic telemetry gear [25]. Recently, O'Brien and Secor [17] studied the effects of thermal stratification on acoustic detection efficiency and range in the thermally stratified waters of the US Southern mid-Atlantic Bight shelf. The thermal stratification of these $10-30 \mathrm{~m}$ deep waters was characterized by a strong summer thermocline capping remnant winter water, so that there could be as much as a $15{ }^{\circ} \mathrm{C}$ temperature difference between surface and bottom waters. Their findings suggest that in most cases, thermal stratification reduced efficiency and range, particularly when the acoustic signal traversed the thermocline. However, they also present new marine data from the mid-Atlantic Bight, where detection range and efficiency increased for signal transmissions within the hypolimnion during strong thermal stratifications. Thus, understanding how thermal stratification influences the transmission of acoustic signals, particularly in freshwater lakes is important, especially as these are the focus of intense research activities $[9,12,20]$.

The sound speed in shallow freshwater lakes is primarily a function of density, and in freshwater lakes, density is primarily a function of temperature. Such sound speed gradients can refract sound waves, such as those produced by acoustic transmitters. In addition, the ambient noise produced by surface waves and wind at the surface of water bodies can also be refracted as it travels, potentially producing a hypolimnetic acoustic environment which is quiet relative to the epilimnion [17]. When thermal stratification defocus sound waves, the refraction can lead to substantial decreases in acoustic signal intensity with distance (Fig. 1). This increased loss is well known in marine systems (e.g., [23]) and has recently been identified as an important limit of detection range in strongly stratified lakes [25]. A transmitted acoustic signal can be visualized as rays emanating from a source, with the distance between the rays being inversely proportional to the acoustic intensity. If there is no thermocline (Fig. 1a), then the main loss of signal strength is through three-dimensional spreading over distance [25]. The detection efficiency thus decreases geometrically with distance, with power inversely decaying as the square of distance. However, once thermal stratification is formed, the refraction of acoustic signals intensifies this three-dimensional spreading loss, and further reduces detection efficiency, and thus reduces the detection range (Fig. 1b, c). In effect, refraction defocusses the sound, spreading out the sound waves even more and thus "dimming" the sound volume arriving at the receiver. Thus, the sound speed gradients lead to a refraction along the path

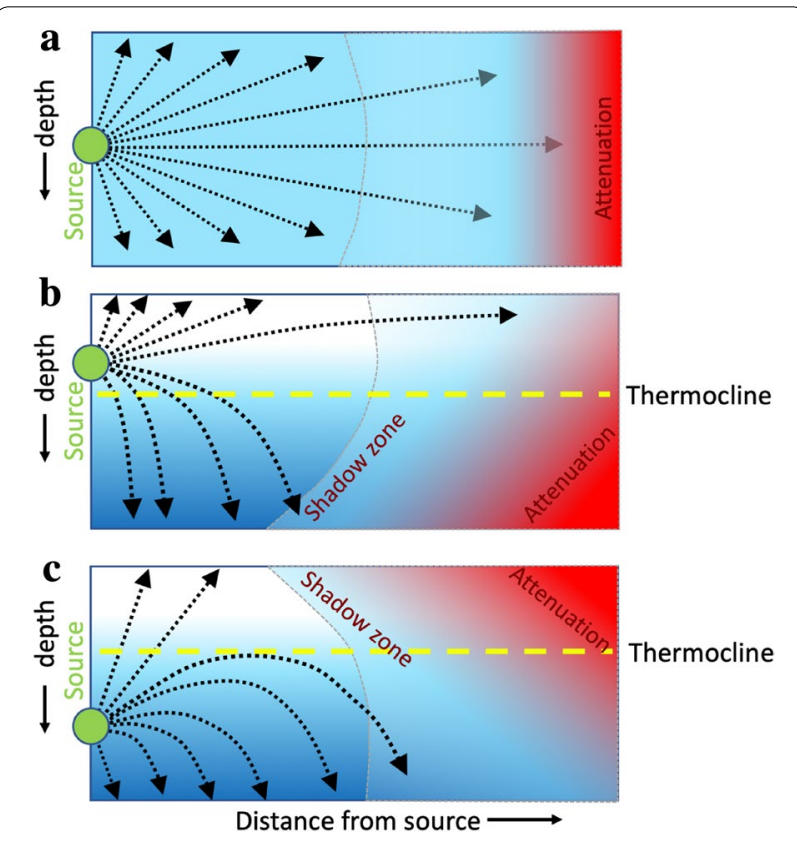

Fig. 1 Illustration of how acoustic signals propagate in isothermal water with signal loss through three-dimensional spreading (a), and how acoustic signals propagate in thermally stratified water with signal loss through three-dimensional spreading that is amplified by refraction when the source is above the thermocline $(\mathbf{b})$ and below thermocline in $\mathbf{c}$. In a the attenuation of acoustic signal is just a function of the distance from the source, whereas in $\mathbf{b}$ an acoustic "shadow zone" of reduced sound intensity forms below the thermocline, while in c an acoustic "shadow zone" forms above the thermocline. The green circle represents the acoustic source, the gradients of blue shading represent speed-of-sound gradients, and red shading represent attenuation of sound intensity. In all sketches, the dashed gray line represents a threshold value of sound intensity below which detection efficiency is poor 
of acoustic signals, which subsequently creates an acoustic shadow zone on the other side of the thermocline that can potentially reduce detection efficiency [24].

In a typical year, the thermal stratification in dimictic Lake Ontario starts to form during May and disappears in October. During the hot summer months, stratification forms with warm surface water and cold bottom water separated by a thermocline, which is a zone where the temperature drops rapidly with depth. Once the surface water temperature cools down in fall, the whole water column mixes due to a combination of wind and buoyancy forcing, and then becomes isothermal. Once the water cools below $4{ }^{\circ} \mathrm{C}$, a winter inverse stratification will form, with ice on top of warmer $4{ }^{\circ} \mathrm{C}$ water $[26,27]$. When the lake warms again in spring, there is another (shorter) isothermal period before summer stratification starts. The vertical temperature difference during winter in Lake Ontario is at most $4{ }^{\circ} \mathrm{C}$, which is significantly smaller than $10-20^{\circ} \mathrm{C}$ difference possible during summer [11]. During stratified periods the depth of a summer thermocline is not static, as the depth of the thermocline can change by as much as $10-20 \mathrm{~m}$ on a daily basis. These changes are caused when wind blows across the lake surface, so that warm water in the surface layer is pushed away to the far end, and downwelling occurs. When wind blows from the opposite direction, upwelling of cold bottom water will occur at the same end of the lake. When the wind stops, several cycles of internal movements can occur over periods of days. As a result, the depth of the thermocline in most large lakes is constantly changing [2]. Consequently, sound speed gradients can be potentially influenced by internal seiches, and hence change on short timescales.

A previous study on detection range in Lake Ontario by Klinard et al. [11] focussed on the period between fall and spring, when the water column was nearly isothermal. During this time the detection range was between 700 and $1700 \mathrm{~m}$ depending on the power outputs and the mooring depths of transmitters, and in extreme cases, signals could travel and be detected up to $9.3 \mathrm{~km}$ [11]. In this study, the receivers were deployed in a ring with spacing of less than $1 \mathrm{~km}$ apart, as this was presumed to guarantee close to $100 \%$ detection efficiency of fish entering and leaving the array of over 60 receivers. However, the majority of the range testing described by Klinard et al. [11] was during the isothermal period when the maximum top to bottom thermal differences throughout the study period were approximately $3{ }^{\circ} \mathrm{C}$, while average differences were less than $0.5^{\circ} \mathrm{C}$. Hence the thermal stratification was likely a minor factor in this previous study. In contrast, during summer in Lake Ontario, top to bottom temperature differences are typically greater than $10^{\circ} \mathrm{C}$ [7]. In Wells et al. [25] observations in the Hamilton Harbour of Lake Ontario suggested the detection range of V13 tags could change between 300 and $500 \mathrm{~m}$ depending upon whether the water column was stratified or isothermal.

In the present study, we extend the previous work of Klinard et al. [11] by focusing on detection efficiency during the stratified summer, rather than focusing on the nearly isothermal winter conditions. In particular we seek to determine how seasonal changes in thermal stratification lead to changes in the detection range of acoustic telemetry tags, due to changes in how the sound signals travel and refract through different sound speed gradients. In this paper, we examine the correlation between sound speed differences and detection efficiency over distances of $150-650 \mathrm{~m}$ in eastern Lake Ontario over a 2-month period during late summer, when there is a transition from very strong thermal stratification to isothermal fall conditions. As well, we categorize sound speed differences into five different levels from low to high to observe the correlation between detection efficiency and distance. All the correlation tests are compared among transmitters deployed at different depths with different power outputs. Our hypothesis is that there is a correlation between sound speed difference and detection efficiency over a certain distance, and how much the detection efficiency is correlated to sound speed difference depends on transmitters and receivers' mooring positions and transmitter power outputs. We then use a mathematical model with field observations as inputs to simulate transmission loss during the stratified period and isothermal period. The influence of thermal stratification based on analysis of field observations and results from mathematical model will then be discussed.

\section{Methods}

\section{Study site}

In this study, the influence of thermal stratification upon detection efficiency was studied in a sentinel array located in the St. Lawrence Channel of eastern Lake Ontario (Fig. 2). Lake Ontario is a very large lake of area $18,960 \mathrm{~km}^{2}$ with a maximum depth of $244 \mathrm{~m}$ and mean depth of $86 \mathrm{~m}$. It is a dimictic lake, meaning that there is strong thermal stratification in summer with surface water temperatures above $20{ }^{\circ} \mathrm{C}$, while the deepest waters are close to $4{ }^{\circ} \mathrm{C}$. There are two extended isothermal periods in fall and spring, and there is a weak inverse thermal stratification in winter when the deepest water is near $4{ }^{\circ} \mathrm{C}$ and surface waters are near $0{ }^{\circ} \mathrm{C}[7,22]$. During summer the thermocline is typically at depths of 20-30 m [7]. In addition to this seasonal variation in temperature, wind stress can tilt the thermocline and result in internal waves [2]. 


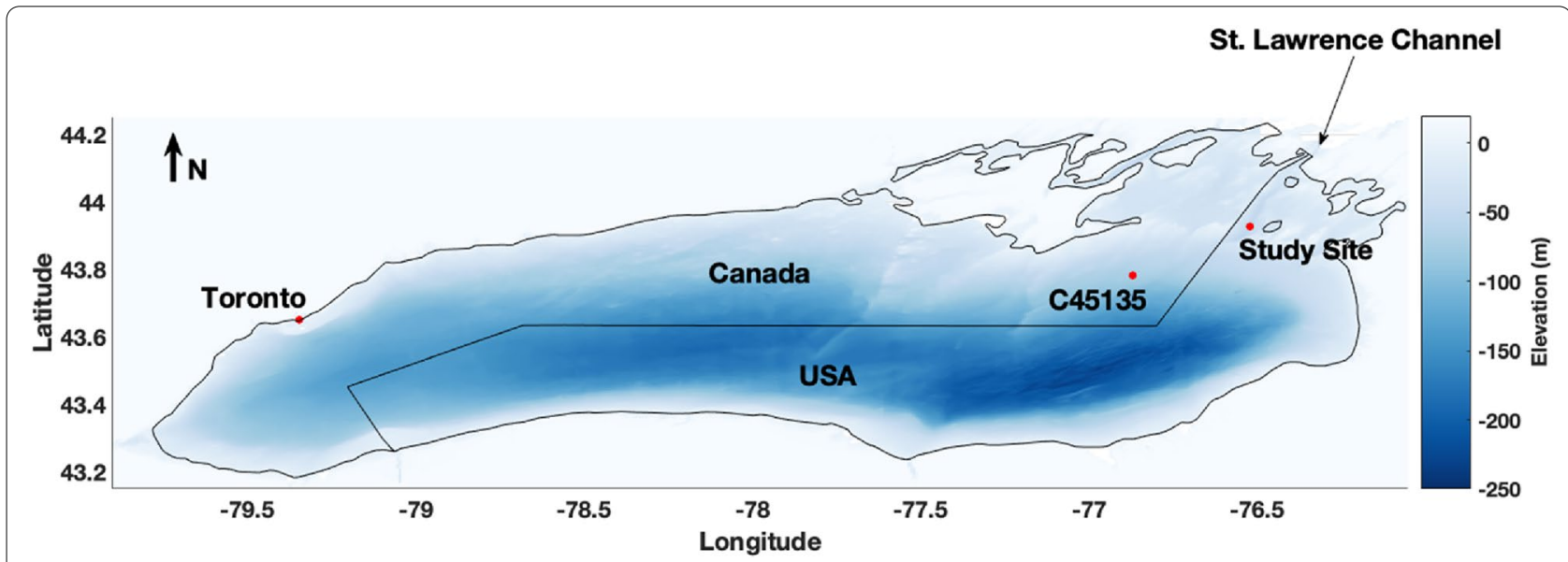

Fig. 2 Bathymetry of Lake Ontario with the transmitter and receiver mooring site located in the St. Lawrence Channel of eastern Lake Ontario (study site), and with location of buoy station C45135 recording wind speed

The eastern end of Lake Ontario typically accumulates ice for several months between January and March [18]. This sentinel array was part of a larger study to investigate the movement and fate of hatchery-reared Bloater (Coregonus hoyi) that were being reintroduced to Lake Ontario [12]. This specific region was chosen for the bloater release due to the presence of a relatively deep region at the lakebed in the St Lawrence channel.

To better understand acoustic range as part of the multiyear bloater study, four receivers (VR2W-69, Vemco Ltd., Bedford, NS, Canada) were deployed on four stationary moorings at approximately $52 \mathrm{~m}$ depth in the channel $\left(43^{\circ} 55.517^{\prime} \mathrm{N}, 76^{\circ} 31.354^{\prime} \mathrm{W}\right)$ with a distance of $150 \mathrm{~m}$, $350 \mathrm{~m}, 450 \mathrm{~m}$, and $650 \mathrm{~m}$ away from the transmitter mooring (Station M5), respectively (Fig. 3). These bottom mounted receivers are typical of most field deployments in the Great lakes, where the valuable receivers must be kept away from potential damage from surface ice or boat traffic. The only downside is we cannot study how signals change as they travel from a source below thermocline to a receiver above the thermocline. All four receivers were deployed at the same time period from August 31st, 2015 to May 25th, 2016. A subset of these data from October 22nd, 2015 to May 23rd, 2016 was previously analyzed in the overwinter study of Klinard et al. [11] - they analyzed this later time-period as there were a total of 85 receivers deployed. In our study, the major findings are based on an earlier time frame from September 7th to October 27th, 2015 which covers the period of the strongest thermal stratification. At the source (Station M5), a chain of HOBO Pendant temperature loggers (accuracy of $\pm 0.21{ }^{\circ} \mathrm{C}$, Onset Computer Corp., Bourne, MA, USA) was deployed every $5 \mathrm{~m}$ from 10 to $50 \mathrm{~m}$ depths. Temperature was recorded hourly. Two transmitters were attached at $11 \mathrm{~m}$ depth, and another two were attached at $50 \mathrm{~m}$ depth (Fig. 3). At both depths, a V9-6x-069k-3 and a V16-6x-069k-3 transmitter (Vemco Ltd., Bedford, NS, Canada) were deployed to generate sound signals every $30 \mathrm{~min}$ (random transmission interval of 1750-1850s) for the entire duration of the study. These transmitter units had power output of 146-151 dB re $1 \mu \mathrm{Pa}$ at $1 \mathrm{~m}$ and of $152-162 \mathrm{~dB}$ re $1 \mu \mathrm{Pa}$ at $1 \mathrm{~m}$, respectively (Vemco Ltd., Bedford, NS, Canada). Winds are taken from the Environment and Climate Change Canada buoy C45135 located at $43^{\circ} 46^{\prime} 48^{\prime \prime} \mathrm{N} 76^{\circ} 52^{\prime} 12^{\prime \prime} \mathrm{W}$.

In this study, we only analyzed both temperature and acoustic telemetry sentinel data from September 7th to October 27th, 2015 (DOY 250 to DOY 300 of 2015). Thus, the analyzed data was a subset of the total field observations, and specifically focuses on the thermally stratified period and subsequent transition period. Daily averaged detection efficiencies and temperatures were calculated for correlating both variables and for subsequent analysis.

\section{Calculation and data analysis}

The sound speed difference, was calculated by comparing sound speed at the top water column $(10 \mathrm{~m})$ and bottom water column (50 m), and was calculated from the formula by Coppens (1981), as 


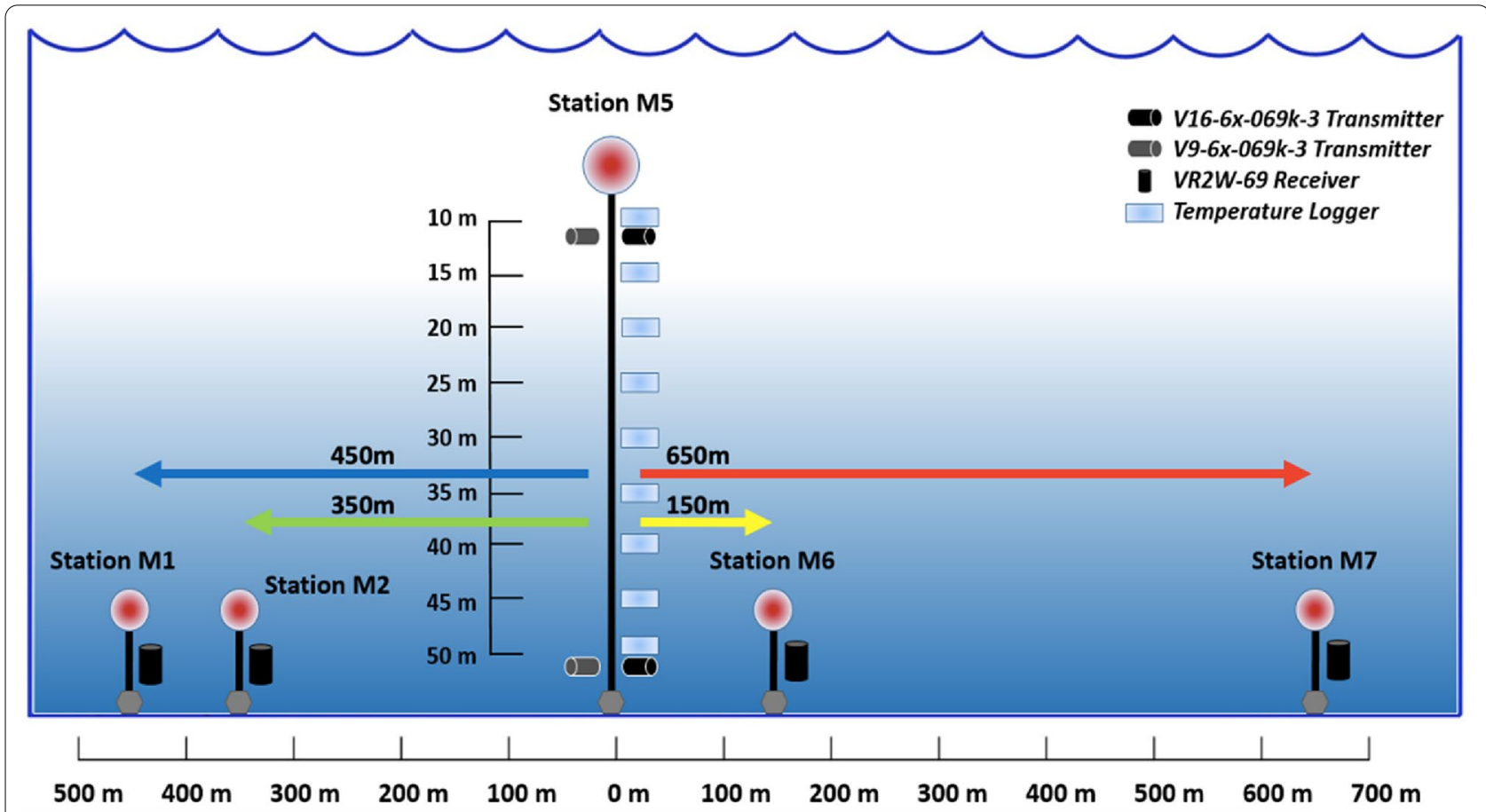

Fig. 3 Detailed description of deployment site with V9 and V16 transmitters deployed along the string of temperature loggers. Four VR2W-69 receiver moorings were located at various distances

$$
\begin{aligned}
\nu_{0}(T)= & 1402.395+5.011 T-5.525 \times 10^{-2} T^{2} \\
& +2.3 \times 10^{-4} T^{3}
\end{aligned}
$$

where $v_{0}$ is the speed-of-sound in units $\mathrm{m} \mathrm{s}^{-1}, T$ is temperature in ${ }^{\circ} \mathrm{C}$, between 0 and $35^{\circ} \mathrm{C}$. During the sampling period, the water temperature varied from 4 to $24^{\circ} \mathrm{C}$, which means the speed-of-sound varied from 1421.6 to $1494.0 \mathrm{~m} \mathrm{~s}^{-1}$.

We estimate how the sound signals could travel under different thermal conditions by using an open-access modelling tool called Bellhop [19]. Bellhop calculates the predicted path of sound waves and generates a visualization of acoustic power losses as the signal spreads away from the source (in this case, the reference fish tags). This publicly available model (http://oalib.hlsresearch.com/AcousticsT oolbox/) can simulate acoustic transmission loss by inputting values of various characteristics, which includes date, depth, source depth, distance, temperature, and speedof-sound conversion equations [19]. To run the Bellhop model, it requires an input environment file which gives users the options to specify properties of upper and lower boundaries, transmitter frequency, number of sources and receivers as well as launching angles. In this study, we used a combination of incoherent acoustic pressure and Gaussian beam bundles to estimate acoustic transmission loss.
One of the main conclusions of Wells et al. [25] was that a drop of $65 \mathrm{~dB}$ in acoustic signal in the Bellhop model correlated with a detection efficiency of $50 \%$ for the V13 transmitters. This resulted in detection ranges reaching as low as $150 \mathrm{~m}$ during stratified conditions (where maximum temperature gradients were $\mathrm{dT} / \mathrm{dz}>1{ }^{\circ} \mathrm{C} / \mathrm{m}$ ) and reaching as high as $450 \mathrm{~m}$ isothermal conditions (where maximum temperature gradients were $\mathrm{dT} / \mathrm{dz}<0.1{ }^{\circ} \mathrm{C} / \mathrm{m}$ ). This threshold is specific to the V13 transmitter that have an output power between 147 and $153 \mathrm{~dB}$ re $1 \mu \mathrm{Pa}$ at $1 \mathrm{~m}$. In contrast the V9 has $145-151 \mathrm{~dB}$ re $1 \mu \mathrm{Pa}$ at $1 \mathrm{~m}$ and $\mathrm{V} 16$ transmitter has $150-162 \mathrm{~dB}$ re $1 \mu \mathrm{Pa}$ at $1 \mathrm{~m}$, so if all else is equal we might expect the detection range to be predicted by slightly different loss thresholds of 63 and $68 \mathrm{~dB}$ for the V9 and V16 units.

\section{Results}

\section{Observations}

The temperature profile shows the transition from summer stratification to fall non-stratified isothermal conditions (Fig. 4a). At the start of our record (DOY 250, Sept. 7th), the water column was strongly stratified in Lake Ontario, with surface temperatures of $24{ }^{\circ} \mathrm{C}$ and bottom temperatures near $4{ }^{\circ} \mathrm{C}$ (the temperature at which water has its maxium density). At the start of the record, a thermocline 


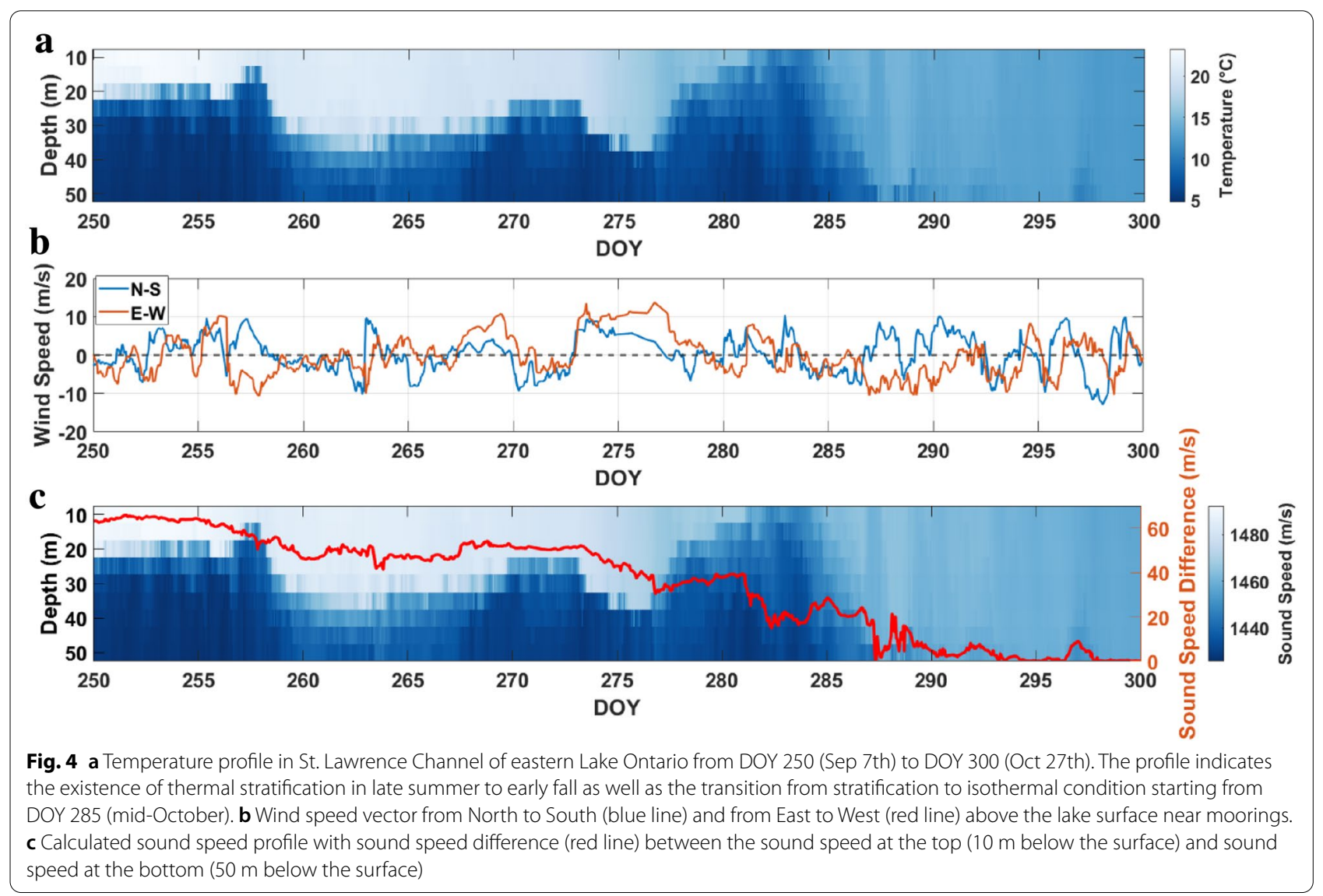

was typically found at depths of $10 \mathrm{~m}$ to $25 \mathrm{~m}$, where the maximum temperature gradients could reach $2.9{ }^{\circ} \mathrm{C} / \mathrm{m}$. The stratification was persistent, although the depth of thermocline changed as several upwelling and downwelling events occurred, whereby the thermocline was depressed to depths of 30-40 m (i.e., between DOY 260 and 275). The fall overturn began around DOY 285 after which the water column became isothermal. During the sampling period, changes in wind speeds and direction could be seen that were related to several wind driven upwelling and downwelling events through DOY 250 to DOY 285 (Fig. 4b).

As sound speed is a function of water temperature, the sound speed gradient was also high at the start of record and reached $10.38 \mathrm{~m} \mathrm{~s}^{-1} / \mathrm{m}$ crossing the thermocline. During the isothermal period the sound speed gradient was lower, and drops to near $0 \mathrm{~m} \mathrm{~s}^{-1} / \mathrm{m}$ in the whole water column. As an example, the sound speed difference could be over $60 \mathrm{~m} \mathrm{~s}^{-1}$ when the water column was strongly stratified from DOY 250 to DOY 255, and reduced to nearly $0 \mathrm{~m} \mathrm{~s}^{-1}$ when the lake became isothermal from DOY 290 to DOY 300 (Fig. 4c).

\section{Correlations among detection efficiency, sound speed difference, and distance}

By correlating the daily average of the sound speed difference with the detection efficiency for the 50 days between DOY 250 and 300, we can determine that sound speed gradients reduce detection efficiency (Fig. 5). During the period studied from DOY 250 to 300 , sound speed differences between the top and bottom of the water column varied from 0 to $65 \mathrm{~m} \mathrm{~s}^{-1}$ (Fig. 4c), the detection efficiency of the V9 transmitter located at $11 \mathrm{~m}$ depth decreased as a function of sound speed difference and distance from source (Fig. 5a).There was a similar trend for the more powerful V16 transmitter located at $11 \mathrm{~m}$ depth (Fig. 5c), but there was less reduction in detection efficiency with increasing sound speed differences. When the transmitter was located below the thermocline at $50 \mathrm{~m}$ depth, a postive relationship between sound speed difference and detection efficiency was found when the transmitter to receiver distance was $350 \mathrm{~m}$ and $450 \mathrm{~m}$ (Fig. 5b). However, for this case, where source and receiver were both below the thermocline, there was virtually no dependence of the 

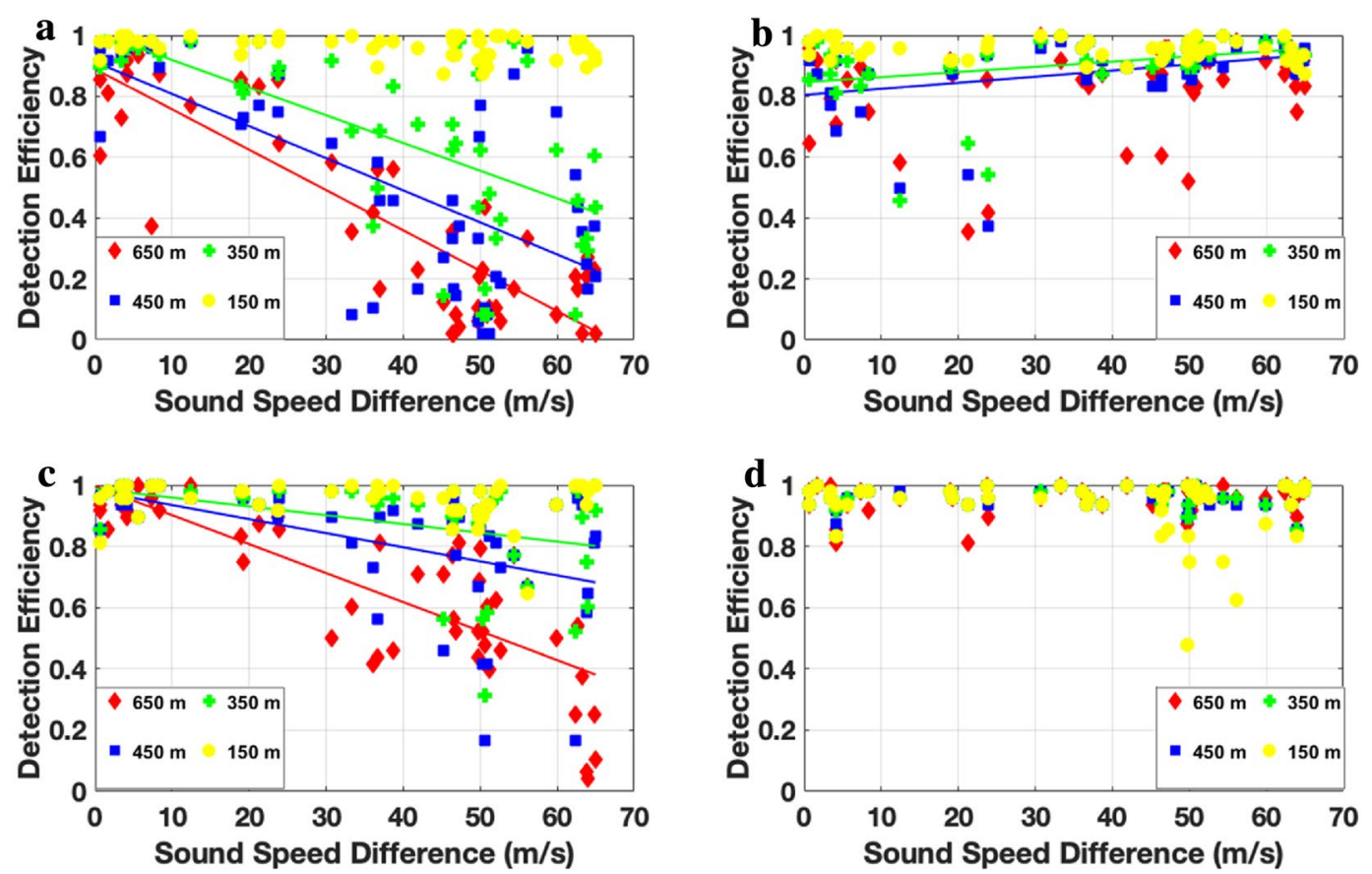

Fig. 5 Comparison between sound speed difference and detection efficiency among four receiver moorings from DOY 250 to DOY 300 for a V9 transmitter at $11 \mathrm{~m}$ depth, $\mathbf{b} \mathrm{V} 9$ transmitter at $50 \mathrm{~m}$ depth, $\mathbf{c} \mathrm{V} 16$ transmitter at $11 \mathrm{~m}$ depth, and $\mathbf{d} \mathrm{V} 16$ transmitter at $50 \mathrm{~m}$ depth. Data were fit with a linear regression model to indicate the relationship between sound speed difference and detection efficiency. Statistics of the model fit are included in Tables 1 and 2

detection efficiency on the sound speed difference across the thermocline (Fig. 5b, d). The average detection efficiencies were higher for the more powerful V16 transmitter (Fig. 5a, c) than the V9 (Fig. 5b, d) but the same general trends are seen.

To understand how the transmitter to receiver distance and sound speed difference affect detection efficiency, we categorized sound speed difference into five different groups, 0-15, 15-30, 30-45, 45-60 and $>60 \mathrm{~m} \mathrm{~s}^{-1}$ (Fig. 6). Similar to the previous results when detection efficiency was a function of sound speed difference, increasing the distance between transmitter and receiver had a negative correlation with detection efficiency. For the V9 tags located at $11 \mathrm{~m}$ depth (i.e., above a thermocline), when sound speed difference was less than $30 \mathrm{~m} \mathrm{~s}^{-1}$, detection efficiency was over $50 \%$ regardless of transmitter to receiver distance (Fig. 6a). As the sound speed difference increased to over $30 \mathrm{~m} \mathrm{~s}^{-1}$ detection efficiency declined rapidly with an average detection efficiency below 50\% when the transmitter to receiver distance reached $450 \mathrm{~m}$. When the sound speed difference reached $45 \mathrm{~m} \mathrm{~s}^{-1}$ detection efficiency at the furthest sound signal receiving station $(650 \mathrm{~m})$ could decline to less than $20 \%$, which suggests most sound signals were lost on their path to the receivers over $650 \mathrm{~m}$ during summer stratification.

For the V16 transmitter, average detection efficiency was above $80 \%$ at each distance when the sound speed difference was below $30 \mathrm{~m} \mathrm{~s}^{-1}$ (Fig. 6c). This means distances less than $650 \mathrm{~m}$ did not play an important role regarding attenuating sound signals in a weakly stratified lake. For a strongly stratified conditions, when the sound speed difference increased above $30 \mathrm{~m} \mathrm{~s}^{-1}$, detection efficiency started declining with distance. However, comparing to observations of V9 transmitter, the higher power output V16 transmitter meant that attenuation induced by the combination of sound speed gradient and travel distance had less impact upon detection efficiency. When the V9 or V16 transmitter were located at $50 \mathrm{~m}$ depth (i.e., beneath the thermocline), the observed detection efficiencies were much higher (Fig. 6b, d). For the V9 transmitter, there was a slight decrease with distance, but efficiency was still greater than $60 \%$ at $650 \mathrm{~m}$ in all cases (Fig. 6b). More strikingly for the V16 transmitter, the detection efficiency was close to $100 \%$ in all cases (Fig. 6d).

The use of the Bellhop model gave a prediction of how the sound signals travel in both stratified and isothermal 

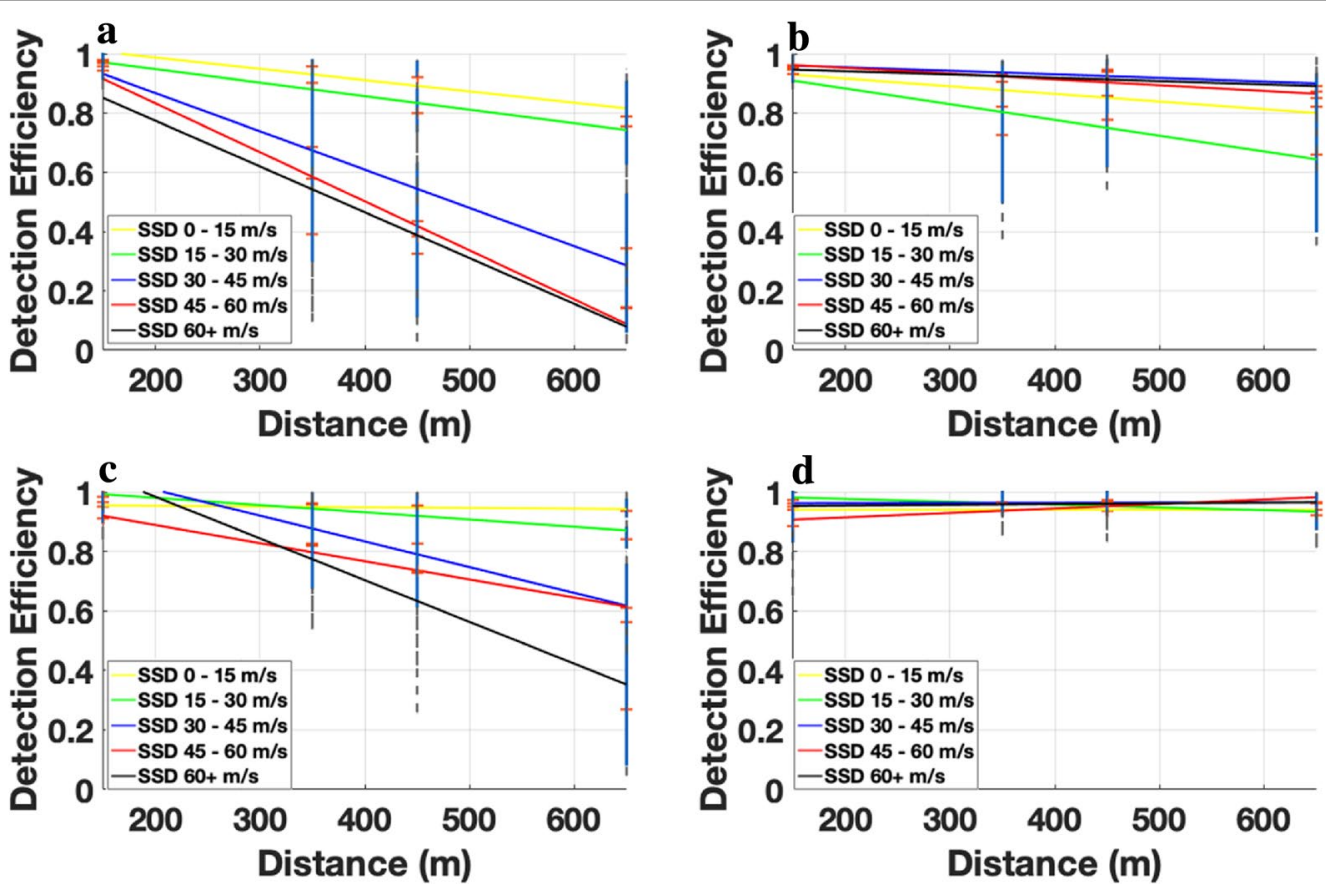

Fig. 6 Range test of detection efficiency categorized by sound speed difference (SSD) indicating the effect of thermal stratification to a V9 transmitter sitting at $11 \mathrm{~m}$ depth, $\mathbf{b} \vee 9$ transmitter sitting at $50 \mathrm{~m}$ depth, $\mathbf{c} \vee 16$ transmitter sitting at $11 \mathrm{~m}$ depth, and $\mathbf{d} \vee 16$ transmitter sitting at $50 \mathrm{~m}$ depth. In these plots, the black broken vertical line is a whisker plot of data from each receiver at the various sounds speed category. For these whisker plots, the red marker is the median, and the vertical blue solid line marks the 25th percentile (bottom end) and 75th percentile (top end)

conditions (Fig. 7). In this case, we selected DOY 250, which is Sept. 7th, as a sample of a stratified condition (Fig. 7a, b), and DOY 300, which is Oct. 27th, as a sample of an isothermal condition (Fig. 7c, d). The Bellhop model needs the water temperature in entire water column, and since temperature loggers were only recording from 10 to $50 \mathrm{~m}$ depths, the water temperature within the surface mixed layer was set to that recorded at the $10 \mathrm{~m}$ depth. As well, parameter settings for Bellhop modeling were the same as in Wells et al. [25]. As mentioned earlier the threshold of $65 \pm 5 \mathrm{~dB}$ loss as a detection limit for the V13 tags would likely be $3 \mathrm{~dB}$ higher for the more powerful V16 tags and $2 \mathrm{~dB}$ lower for the weaker V9 tags. In these plots, the loss of signal was shown - the main feature was that the signal loss increased with distance from the source, reflecting the spherical spreading of acosutic sound. The details of the patterns of loss change with stratification. For the case, where the transmitter was located at $11 \mathrm{~m}$ depth, there was greater attenuation of sound below the thermocline, so that a threshold of $63 \mathrm{~dB}$ and $68 \mathrm{~dB}$ loss of signal was reached at $50 \mathrm{~m}$ depth at $310 \mathrm{~m}$ and $367 \mathrm{~m}$, respectively, from the source (Fig. 7a). For comparison, there is a zone of lower signal loss above the thermocline, so starting at around $300 \mathrm{~m}$ the region below the thermocline can be termed an acoustic "shadow zone", where the strength of acoustic signals become relatively "dimmed" due to divergence of sound signals, as sketched in Fig. 1b. When the source is located at the $50 \mathrm{~m}$ depth, the threshold was reached at $50 \mathrm{~m}$ depth at $432 \mathrm{~m}$ and $594 \mathrm{~m}$, respectively, from the source (Fig. 7b). It is important to note that in this case with the source below the thermocline, there was also an acoustic "shadow zone" above the thermocline, where signal loss was greater (as sketched in Fig. 1c). When isothermal conditions were used and the source was at $11 \mathrm{~m}$ or $50 \mathrm{~m}$, the threshold of $63 \mathrm{~dB}$ and $68 \mathrm{~dB}$ loss of signal was rached at $50 \mathrm{~m}$ depth at $410 \mathrm{~m}$ and $510 \mathrm{~m}$, respectively, away from the source for both case (Fig. 7c, d). Such a tendency indicated that in the isothermal cases, there was much less variation with depth of the modelled acoustic loss, and that contours for the $63 \mathrm{~dB}$ and $68 \mathrm{~dB}$ loss occured at larger distances than in the thermally stratified conditions (Fig. 7a, b).

\section{Discussion}

The sound speed difference between top and bottom water column that exists in a large, deep freshwater lake has a strong influence on the detection efficiency of acoustic telemetry equipment. In general, there was a negative relationship between sound speed difference 

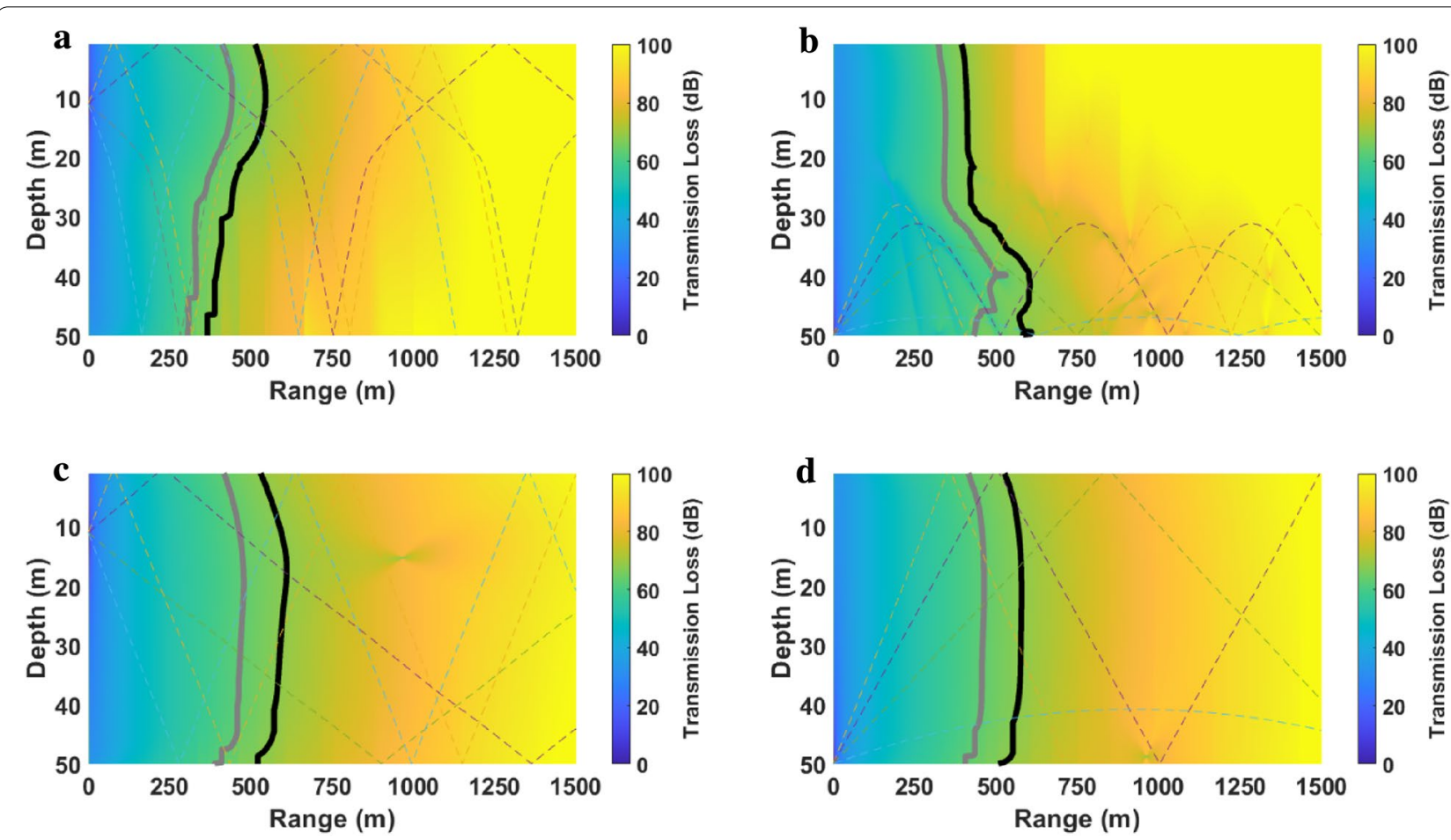

Fig. 7 Bellhop model predicts transmission loss and ray propagation on a DOY 250 (summer stratified conditions) with transmitter sitting at $11 \mathrm{~m}$, b DOY 250 with transmitter sitting at $50 \mathrm{~m}$, c DOY 300 (fall isothermal conditions) with transmitter sitting at $11 \mathrm{~m}$, and d DOY 300 with transmitter sitting at $50 \mathrm{~m}$. Two thresholds of transmission loss of $63 \mathrm{~dB}$ and $68 \mathrm{~dB}$ are indicated with grey line and black line, respectively. The faint dashed lines are a selection of the trajectories of acoustic rays used by the Bellhop model-the key feature is they are straight lines in isothermal conditions and they bend in stratified conditions, and that they reflect from boundaries

and detection efficiency (Figs. 5 and 6), and the $R$ square and adjusted $R$ square values indicate how much they were correlated (Tables 1 and 2). With tested $p$ values less than 0.05 , the results from each set of comparison were significant. The sound speed difference was calculated as the difference in sound speed at $10 \mathrm{~m}$ and $50 \mathrm{~m}$ depth in the water column and thus indicated the presence of a strong gradient between these depths. Hence, the correlation between sound speed difference and detection efficiency we observed was expected when the transmitters sit at $11 \mathrm{~m}$ depth and receivers sit at $50 \mathrm{~m}$ depth, so that acoustic signals must cross the thermocline (Fig. 5a, c). The strong relationship between sound speed difference and detection efficiency at $650 \mathrm{~m}$ in the linear regression indicated that more than half of the detection efficiency data at this distance can be explained by sound speed difference. In addition, weak correlations could be observed at transmitter-to-receiver distances of $350 \mathrm{~m}$ and $450 \mathrm{~m}$ in the V9 transmitter data set (Fig. 5a); however, that correlation of transmitter to receiver distance became lower in V16 transmitter data set (Fig. 5c), which could mean the more powerful V16 transmitters are less impacted by these sound speed changes over the ranges up to $650 \mathrm{~m}$ considered here. The lack of correlation between sound speed difference and detection efficiency at transmitter-toreceiver distances of $150 \mathrm{~m}$ and depths of $11 \mathrm{~m}$ for both the V9 and V16 transmitters indicates sound speed difference would not cause attenuation of sound signals at short distances (Fig. 5b, d). When both transmitter and receiver were below the thermocline, the vertical sound speed difference was not important regarding sound signal attenuation (Fig. 5b, d). However, for the V9 transmitter data set, when transmitter to receiver distances were $350 \mathrm{~m}$ and $450 \mathrm{~m}$, a weak positive relationship between sound speed difference and detection efficiency was observed (Fig. 5b), which is consistent with the findings of slight increases in range when source and receiver are both located under a thermal stratification [17]. Our Bellhop modelling also showed the increase of detection range when both source and receiver were located at $50 \mathrm{~m}$ depth in stratified conditions, as compared to isothermal condition (Fig. 7b, d). While it was not a strong trend, it is interesting that same phenomenon induced by thermal stratification could be observed in Lake Ontario, as in the coastal ocean setting 
of O'Brien and Secor [17]. Although bottom increase of detection efficiency was observed in the field, we only saw a strong correlation at distance of 350 and $450 \mathrm{~m}$, at smaller distances there was no trend as detection efficiency was always near $100 \%$, while for greater distances of $650 \mathrm{~m}$ we found a lot of scatter so could not fit a trend line (Fig. 5b, d). The general trends in changes in detection range with stratification and speed of sound gradient that we observed in Lake Ontario are consistent with the modelling predictions (Fig. 7). When a source is located above the thermocline, the detection range is reduced below the thermocline compared to non-stratified conditions. When the source is located below the thermocline, there is little difference in range measured at $50 \mathrm{~m}$ depth, although an acoustic shadowzone is visible in modelling above thermocline.

There were a number of processes that lead to changes in thermal structure of eastern Lake Ontario between DOY 250 and 300 (Fig. 4). The overall reduction in the strength of thermal stratification, along with the increasing depth of thermocline, is due to cooling air temperatures in the transition from summer to fall. Thus, the water column became nearly isothermal after DOY 290, and there is a consistent decreasing trend in the difference in sound speed between the top and bottom of the water column (red line in Fig. 4c). In addition to these slow changes in thermal structure, the wind blowing over Lake Ontario can drive large amplitude internal waves that result in variability of thermal structure on a timescale of days to weeks. Such wind driven movements of thermocline are a ubiquitous feature of all large lakes $[4,5]$ and typically, these changes in depth of thermocline occur on timescales of days. Every time the wind blows over the surface of sampling site, the thermocline tends to depress at the downwind end and elevate at the upwind end. The influence of the Coriolis force shifts the direction of surface currents to the right, so that as our site is at the eastern end of Lake Ontario, winds from the west and south lead to downwelling of the thermocline, whereas winds from the east and north lead to upwelling. These changes in depth of the thermocline are seen most strikingly in change of wind direction between DOY 270 and 275 . When the wind stops blowing over the surface, the thermocline oscillates before it becomes stably horizontal [25]. In our record, the magnitude and direction of wind was constantly changing throughout the stratified period, thus caused changes of its depths (Fig. 4b).

It is worth comparing the detection ranges found during these strongly stratified summer period, with the larger ranges found during the weakly stratified or isothermal time-period studied by Klinard et al. [11]. They found that over winter in the mainly unstratified conditions that detection range from the transmitter at $11 \mathrm{~m}$ was $700 \mathrm{~m}$ the V9 and 1300-1400 $\mathrm{m}$ for V16, and for the transmitter located at $50 \mathrm{~m}$ depth was $1100-1200$ for the V9 and $1700 \mathrm{~m}$ for the V16 unit. During the winter period there was some weak inverse stratification, which might explain the larger ranges for the deeper transmitter. During the earlier summer period we analyzed at the same site, the furthest receivers was $650 \mathrm{~m}$ away from the transmitter, whereas in Klinard et al. [11] a greater number of receivers were used, so they could estimate longer detections ranges. For instance, the data in Fig. $6 \mathrm{~b}$, d suggests that detection ranges could be greater than $650 \mathrm{~m}$ during summer for the more powerful transmitters. During the late summer, when there were very strongly stratified conditions, the range could be as low as $350 \mathrm{~m}$. This shows the importance of summer stratification in changing the efficiency of the bloater array, where the receivers were spaced approximately $1 \mathrm{~km}$ apart based on the expected detection efficiency of $80 \%$ at $600 \mathrm{~m}$ [11].

Based upon our study we can make some recommendations for improving field deployments in thermally stratified systems. First, it is important to measure temperature profiles, to be aware of possible thermal stratification influences. This should be done at start and end of deployments, and ideally as a continuous record with an in-situ chain of thermistors. We recommend the use of sentinel tags, which would show if there is a change in range associated with the changes in depth and strength of the thermocline. In addition, depending on where fish are expected to sit in water column, it would be advantageuous to deploy receivers on both sides of the thermocline, so that shadow-zones are minimized.

Some species of fish in Lake Ontario occupy specific depths ranges at certain times of the year, so the influences of acoustic refraction upon detection can be estimated. For instance, in Klinard et al. [11] the target species was the hypolimnetic dwelling bloater (Coregonus hoyi), so there would be no influence of the thermocline upon the detection range as there are no sound speed gradient between the tags and receivers. Other pelagic fishes, such as walleye (Sander vitreus), American eel (Anguilla rostrata), smallmouth bass (Micropterus dolomieu), muskellunge (Esox masquinongy) and lake trout (Salvelinus namaycush), typically occupy species-specific temperature and dissolved oxygen ranges imposed by physiological requirements [6].

In most temperate lakes during the summer, thermal stratification physically partitions the lake into different zones suitable for different thermal guilds. Coldwater fishes that avoid warm waters typically reside in the cold hypolimnion, with the thermocline creating a sharp upper boundary, both in terms of temperature and depth. However, coldwater fish will make foraging trips into warmer waters and cross the thermocline. For example, lake trout in smaller lakes will move into the littoral zone to feed [6] 
and a subset of Lake Ontario lake trout have been shown to cross the thermocline to feed [20]. Similarly, cool water fish would sit near the thermocline, and warm water fish at or above the thermocline. Here again, some warmwater species, such as Chinook salmon (Oncorhynchus tshawytscha), will make trips below the thermocline, presumably to make digestion more efficient [20]. As most receivers are located below the thermocline, it is likely that warm water fish would be most influenced by reduced detection range due to the sound speed gradients but cold or deepwater fish that cross the thermocline to feed would also be influenced during these movements. Fish might also be confined above the thermocline due to anoxia in the hypolimnion, as occurs routinely the central basins on Lake Erie [1], Green Bay in Lake Michigan [13] and Hamilton Harbour in Lake Ontario [4, 5, 25]. In these locations, benthic receivers would have reduced range for fish above the thermocline.

The seasonal cycle of stratification is important to consider when interpreting fish telemetry data, because tagged fish typically have specific thermal preferences and may use different parts of the lake during different seasons [9]. For example, the bottom of many lakes lacks oxygen during the summer months, resulting in fish actively avoiding the deep waters (e.g., $[14,21])$. With the presence of a thermocline, this behaviour has implications for the interpretation of acoustic telemetry data, because detection performance can vary depending on the depth of acoustic receivers relative to the thermal layer that the tagged fish chooses to occupy. Understanding the influence of thermal gradients on detection efficiency of telemetry equipment will facilitate more accurate analysis and interpretation of cross-seasonal telemetry data. Thus, an important first step to take in future telemetry studies, would be to measure the changes in thermal stratification that occur on timescales of days to months, and to make use of sentinel tags in mooring designs.

\section{Conclusion}

During summer most large lakes in mid-latitudes are thermally stratified with a warm surface layer seperated from a cold hypolimnion by a sharp thermocline. Such strong thermoclines produce rapid changes in sound speed, which refract and dim acoustic signals that cross the thermocline. Our study revealed that acoustic telemetry detection efficiency decreased significantly for signals crossing the thermocline when the thermal gradient was high, and there was temperature differences between top and bottom of water column up to $17^{\circ} \mathrm{C}$. In these summer conditions, we found that ranges could be limited to distances between 350 and $550 \mathrm{~m}$. By contrast, detection efficency remained high when the thermal gradient was small, and when the top to bottom temperature differences was less than $4{ }^{\circ} \mathrm{C}$, we observed a detection range up to $650 \mathrm{~m}$. A similar reduction of detection efficiency was not observed for signals that did not cross the thermocline, so that when both the source and reciever were located at the lakebed the detection efficiencies were generally higher. In this study, the thermocline's depth was dynamic and varied at a timescale of days; therefore, acoustic detection range could vary at similar timescales. Refraction of sound mainly influences detection range and detection efficiency when acoustic signals cross the thermocline but not when the tranmitter and receiver are on the same side of the thermocline. As most acoustic receivers are bottom-mounted (i.e., below most thermoclines in dimitcic lakes), anticipating and measuring the tagged animals vertical position relative to the thermocline is an important consideration when designing acoustic telemetry studies and interpreting data.

\section{Appendix}

See Tables 1, 2.

Table 1 Summary of coefficient of determination ( $R$ square), adjusted coefficient of determination (Adj. $R$ square), and $p$ value for the linear fit of sampled data retreived from four sets of receivers located $150 \mathrm{~m}$ (M6), $250 \mathrm{~m}$ (M2), $350 \mathrm{~m}$ (M1), and $650 \mathrm{~m}$ (M7) away from the source

\begin{tabular}{lcll}
\hline & \multicolumn{1}{c}{ R square } & Adj. $\boldsymbol{R}$ square & $\boldsymbol{p}$ value \\
\hline SSD-DE 57350 (Fig. 5a) & & \\
M7 (Red) & 0.7439 & 0.7385 & $8.4 \times 10^{-16}$ \\
M1 (Blue) & 0.4525 & 0.4411 & $8.7 \times 10^{-8}$ \\
M2 (Green) & 0.4265 & 0.4146 & $2.7 \times 10^{-7}$ \\
M6 (Yellow) & 0.09441 & 0.07554 & 0.475 \\
SSD-DE 57349 (Fig. 5b) & & \\
M7 (Red) & 0.03702 & 0.01696 & 0.181 \\
M1 (Blue) & 0.1389 & 0.121 & 0.0077 \\
M2 (Green) & 0.1458 & 0.128 & 0.0062 \\
M6 (Yellow) & 0.02274 & 0.00238 & 0.296 \\
SSD-DE 30850 (Fig. 5c) & & \\
M7 (Red) & 0.6194 & 0.6115 & $1.2 \times 10^{-11}$ \\
M1 (Blue) & 0.2339 & 0.2179 & 0.00037 \\
M2 (Green) & 0.1713 & 0.154 & 0.0028 \\
M6 (Yellow) & 0.01069 & -0.009923 & 0.475 \\
SSD-DE 30848 (Fig. 5d) & & \\
M7 (Red) & 0.05388 & 0.03417 & 0.105 \\
M1 (Blue) & 0.03633 & 0.01625 & 0.185 \\
M2 (Green) & 0.04345 & 0.02352 & 0.146 \\
M6 (Yellow) & 0.02962 & 0.009405 & 0.232 \\
\hline
\end{tabular}

Higher $R$ square and adj. $R$ square means variables are more relevant. With $p$ value less than 0.05 , the result is significant 
Table 2 Summary of coefficient of determination ( $R$ square), adjusted coefficient of determination (Adj. $R$ square), and $p$ value for the linear fit of five sound speed difference categories

\begin{tabular}{cccl}
\hline & \multicolumn{1}{c}{$\boldsymbol{R}$ square } & Adj. $\boldsymbol{R}$ square & $\boldsymbol{p}$ value \\
\hline Distance-DE Bplot (Fig. 6a) & & \\
0-15 m/s (Yellow) & 0.3275 & 0.3115 & 0.000049 \\
$15-30 \mathrm{~m} / \mathrm{s}$ (Green) & 0.5344 & 0.5086 & 0.00025 \\
$30-45 \mathrm{~m} / \mathrm{s}$ (Blue) & 0.6218 & 0.6073 & 0.00000062 \\
$45-60 \mathrm{~m} / \mathrm{s}$ (Red) & 0.6391 & 0.6342 & $4.8 \times 10^{-18}$ \\
$60+\mathrm{m} / \mathrm{s}$ (Black) & 0.7512 & 0.7429 & $1.4 \times 10^{-10}$ \\
Distance-DE Bplot (Fig. 6b) & & \\
0-15 m/s (Yellow) & 0.1339 & 0.1133 & 0.014 \\
$15-30 \mathrm{~m} / \mathrm{s}$ (Green) & 0.2117 & 0.1679 & 0.041 \\
$30-45 \mathrm{~m} / \mathrm{s}$ (Blue) & 0.1802 & 0.1486 & 0.024 \\
$45-60 \mathrm{~m} / \mathrm{s}$ (Red) & 0.1852 & 0.1741 & 0.00010 \\
$60+\mathrm{m} / \mathrm{s}$ (Black) & 0.1639 & 0.136 & 0.022 \\
Distance-DE Bplot (Fig. 6c) & & \\
$0-15 \mathrm{~m} / \mathrm{s}$ (Yellow) & 0.008616 & -0.01499 & 0.549 \\
$15-30 \mathrm{~m} / \mathrm{s}$ (Green) & 0.4623 & 0.4325 & 0.00097 \\
$30-45 \mathrm{~m} / \mathrm{s}$ (Blue) & 0.6526 & 0.6392 & 0.00000020 \\
$45-60 \mathrm{~m} / \mathrm{s}$ (Red) & 0.324 & 0.3148 & $8.1 \times 10^{-8}$ \\
$60+\mathrm{m} / \mathrm{s}$ (Black) & 0.6272 & 0.6148 & $6.7 \times 10^{-8}$ \\
Distance-DE Bplot (Fig. 6d) & & 0.99 \\
$0-15 \mathrm{~m} / \mathrm{s}$ (Yellow) & 0.00000619 & -0.0238 & 0.091 \\
$15-30 \mathrm{~m} / \mathrm{s}$ (Green) & 0.1505 & 0.1033 & 0.80 \\
$30-45 \mathrm{~m} / \mathrm{s}$ (Blue) & 0.00252 & -0.03584 & 0.0036 \\
$45-60 \mathrm{~m} / \mathrm{s}$ (Red) & 0.1092 & 0.09712 & \\
$60+\mathrm{m} / \mathrm{s}$ (Black) & 0.008892 & -0.02415 & 0.61 \\
\hline
\end{tabular}

Higher $R$ square and adj. $R$ square means variables are more relevant. With $p$ value less than 0.05 , the result is significant

\section{Acknowledgements}

This work would not have been possible with out the help and skill of the crews of the OMNRF Lake Ontario Explorer and NYSDEC Seth Green, particularly captain Jon Chicoine and captain Alan Fairbanks, respectively. This research was supported by funding provided by NSERC to YK and MGW, Great Lakes Fishery Commission Grant to ATF, TBJ and EAH (Project ID_2015_FIS_44040 and 2017_JOH_44065), Canada-Ontario Agreement on Great Lakes Water Quality and Ecosystem Health to TBJ, MITACs Grant to ATF and EAH, and USFWS Grant to ATF, TBJ and EAH.

\section{Authors' contributions}

YK analyzed the data and led the writing of this paper; EAH, ATF and TBJ designed the methodology and collected the data; MGW conceptualized and supervised the study; EAH, ATF, TBJ, NVK, DMW, SJS contributed in writing and editing. All authors read and approved the final manuscript.

\section{Funding}

Prof. Mathew G. Wells was funded by NSERC (RGPIN-2016-06542, EGP-53831419). Prof. Aaron T. Fisk, Dr. Timothy B. Johnson, and Dr. Edmund A. Halfyard were funded by Great Lakes Fishery Commission (Project ID_2015_FIS_44040 and 2017_JOH_44065). Dr. Timothy B. Johnson was funded by Canada-Ontario Agreement on Great Lakes Water Quality and Ecosystem Health. Prof. Aaron T. Fisk and Dr. Edmund A. Halfyard were funded by MITACs. Prof. Aaron T. Fisk, Dr. Timothy B. Johnson, and Dr. Edmund A. Halfyard were funded by USFWS.

\section{Availability of data and materials}

The data sets used and/or analyzed during this study are available from the corresponding author upon request.

\section{Declarations}

Ethics approval and consent to participate

Not applicable.

\section{Consent for publication}

Not applicable.

\section{Competing interests}

The authors declare that they have no completing interests.

\section{Author details}

${ }^{1}$ Department of Physical and Environmental Sciences, University of Toronto Scarborough, Toronto, ON, Canada. ${ }^{2}$ Great Lakes Institute for Environmental Research, University of Windsor, Windsor, ON, Canada. ${ }^{3}$ Present Address: Department of Biology, Dalhousie University, Halifax, NS, Canada. ${ }^{4}$ Glenora Fisheries Station, Ontario Ministry of Natural Resources and Forestry, Picton, ON, Canada. ${ }^{5}$ Nova Scotia Salmon Association, Bedford, NS, Canada. ${ }^{6}$ VEMCO, 20 Angus Morton Drive, Bedford, NS, Canada.

Received: 27 May 2021 Accepted: 11 November 2021

Published online: 25 November 2021

\section{References}

1. Chamberlin DW, Knight CT, Kraus RT, Gorman AM, Xu W, Collingsworth PD. Hypoxia augments edge effects of water column stratification on fish distribution. Fish Res. 2020;231:105684.

2. Chowdhury MR, Wells MG, Howell T. Movements of the thermocline lead to high variability in benthic mixing in the nearshore of a large lake. Water Resour Res. 2016;52(4):3019-39.

3. Cooke SJ, Hinch SG, Wikelski M, Andrews RD, Kuchel LJ, Wolcott TG, et al. Biotelemetry: a mechanistic approach to ecology. Trends Ecol Evol. 2004;19(6):334-43.

4. Flood B, Wells MG, Dunlop E, Young J. Vertical oscillations of the thermocline caused by internal waves modify coldwater pelagic fish distribution: results from a large stratified lake. J Great Lakes Res. 2021;47(5):1386-99.

5. Flood B, Wells MG, Midwood JD, Brooks J, Kuai Y, Li J. Intense variability of dissolved oxygen and temperature in the internal swash zone of Hamilton Harbour, Lake Ontario. Inland Waters. 2021. p. 1-18.

6. Guzzo MM, Blanchfield PJ, Rennie MD. Behavioral responses to annual temperature variation alter the dominant energy pathway, growth, and condition of a cold-water predator. P Natl Acad Sci USA. 2017;114(37):9912-7.

7. Huang A, Rao YR, Lu Y, Zhao J. Hydrodynamic modeling of Lake Ontario: an intercomparison of three models. J Geophys Res-Oceans. 2010;115(C12).

8. Hussey NE, Kessel ST, Aarestrup K, Cooke SJ, Cowley PD, Fisk AT, et al. Aquatic animal telemetry: a panoramic window into the underwater world. Science. 2015;348(6240):1255642-1255642.

9. Ivanova SV, Johnson TB, Metcalfe B, Fisk AT. Spatial distribution of lake trout (Salvelinus namaycush) across seasonal thermal cycles in a large lake. Freshwater Biol. 2020;66(4):615-27.

10. Kessel ST, Cooke SJ, Heupel MR, Hussey NE, Simpfendorfer CA, Vagle S, et al. A review of detection range testing in aquatic passive acoustic telemetry studies. Rev Fish Biol Fisher. 2014:24(1):199-218.

11. Klinard NV, Halfyard EA, Matley JK, Fisk AT, Johnson TB. The influence of dynamic environmental interactions on detection efficiency of acoustic transmitters in a large, deep, freshwater lake. Anim Biotelemetry. 2019;7(1):1-17.

12. Klinard NV, Matley JK, Halfyard EA, Connerton M, Johnson TB, Fisk AT. Poststocking movement and survival of hatchery-reared bloater (Coregonus hoyi) reintroduced to Lake Ontario. Freshwater Biol. 2020;65(6):1073-85.

13. Klump JV, Brunner SL, Grunert BK, Kaster JL, Weckerly K, Houghton EM, et al. Evidence of persistent, recurring summertime hypoxia in Green Bay. Lake Michigan J Great Lakes Res. 2018;44(5):841-50.

14. Kraus RT, Knight CT, Farmer TM, Gorman AM, Collingsworth PD, Warren GJ, et al. Dynamic hypoxic zones in Lake Erie compress fish habitat, altering vulnerability to fishing gears. Can J Fish Aquat Sci. 2015;72(6):797-806.

15. Loher T, Webster RA, Carlile D. A test of the detection range of acoustic transmitters and receivers deployed in deep waters of Southeast Alaska, USA. Anim Biotelemetry. 2017;5(1):1-22. 
16. Mathies NH, Ogburn MB, McFall G, Fangman S. Environmental interference factors affecting detection range in acoustic telemetry studies using fixed receiver arrays. Mar Ecol Prog Ser. 2014;495:27-38.

17. O'Brien M, Secor D. Influence of thermal stratification and storms on acoustic telemetry detection efficiency: a year-long test in the US Southern Mid-Atlantic Bight. Anim Biotelemetry. 2021;9(1):1-12.

18. Oveisy A, Boegman L, Imberger J. Three-dimensional simulation of lake and ice dynamics during winter. Limnol Oceanogr. 2012;57(1):43-57.

19. Porter MB. The Bellhop manual and user's guide: Preliminary draft. Heat, Light, and Sound Research, Inc., La Jolla, Tech. Rep. 2011.

20. Raby GD, Johnson TB, Kessel ST, Stewart TJ, Fisk AT. Pop-off data storage tags reveal niche partitioning between native and non-native predators in a novel ecosystem. J Appl Ecol. 2019;57(1):181-91.

21. Roberts JJ, HöökTO, Ludsin SA, Pothoven SA, Vanderploeg HA, Brandt SB. Effects of hypolimnetic hypoxia on foraging and distributions of Lake Erie yellow perch. J Exp Mar Biol Ecol. 2009;381:S132-42.

22. Rodgers GK. Time of onset of full thermal stratification in Lake Ontario in relation to lake temperatures in winter. Can J Fish Aquat Sci. 1987:44(12):2225-9.

23. Shi $\mathrm{H}$, Kruger $\mathrm{D}$, Nickerson JV. Incorporating environmental information into underwater acoustic sensor coverage estimation in estuaries. IEEE Milit Commun C. 2007. p. 1-7.

24. Urick RJ. Principles of underwater sound. Baskerville: Peninsula Publishing; 1983.

25. Wells MG, Li J, Flood B, Brooks JL, Cooke SJ, Kuai Y, et al. Speed-of-sound gradients due to summer thermal stratification can reduce the detection range of acoustic fish tags: results from a field study in Hamilton Harbour. Ontario Can J Fish Aquat Sci. 2021;78(3):269-85.

26. Yang B, Young J, Brown L, Wells MG. High-frequency observations of temperature and dissolved oxygen reveal under-ice convection in a large lake. Geophys Res Lett. 2017:44(24):12218-26.

27. Yang B, Wells MG, Li J, Young J. Mixing, stratification, and plankton under lake-ice during winter in a large lake: implications for spring dissolved oxygen levels. Limno Oceanogr. 2020;65(11):2713-29.

\section{Publisher's Note}

Springer Nature remains neutral with regard to jurisdictional claims in published maps and institutional affiliations.

Ready to submit your research? Choose BMC and benefit from:

- fast, convenient online submission

- thorough peer review by experienced researchers in your field

- rapid publication on acceptance

- support for research data, including large and complex data types

- gold Open Access which fosters wider collaboration and increased citations

- maximum visibility for your research: over $100 \mathrm{M}$ website views per year

At BMC, research is always in progress.

Learn more biomedcentral.com/submissions 